\title{
Evaluation of marine gas turbine engine parameters in terms of exhaust harmful emissions
}

The article presents an analysis of the use of gas turbine engine in the propulsion and marine power plant of vessels, taking into account environmental aspects. The preliminary results of emission tests of harmful exhaust emissions of the laboratory gas turbine engine were presented. Also an analysis was also undertaken on the possibility of carrying out measurements of concentrations of pollutants in the marine gas turbine engine propulsion systems in terms of its operation on the vessel.

Key words: harmful compounds, emission, exhaust gases, marine gas turbine engine

\section{Introduction}

Energy requirements of maritime transport arising from their operational needs related to the function of the movement of the vessel and their existential functions has long been carried out by using mainly internal combustion piston engines.

In the case of gas turbine engines, depending on the destination of the vessel and energy needs, power units and marine power plant with steam turbines are used in cases where nuclear power plants and systems with the so-called gas turbines in the form of gas turbine engines are used.

As a result of smaller energy efficiency and the resulting higher fuel consumption, gas turbine engines for marine use are being replaced by piston engines and represent only a few percent share in the total population of marine internal combustion engines. However, gas turbine engines have one significant advantage - they are characterized by a high concentration of power expressed as a ratio obtained under the terms of the weight of the engine. In comparison, the vessels power must take into account not only the weight but the mass of the entire engine propulsion unit, since the use of the gas turbine engine requires the use of additional reduction of gear rotational speed of the motor drive shaft to the desired speed of the vessel propulsion. The list compares power, economic and technical parameters conducted for piston and gas turbine engines used for main propulsion and the validity of the use of gas turbine engines for propulsion of warships is achieved.

In connection with a significant quantitative predominance of marine internal combustion piston engines of the vessel's gas turbine engines, legal regulations concerning the emission of harmful exhaust gases of marine engines are mainly with regard to piston engines (Table 1). One of these acts is the International Convention for the Prevention of Pollution from Ships of 1973, Signed in London on 2 November 1973 as amended by the Protocol compiled in London on 17 February 1978 (Journal of Laws of 1987 No. 17, item 101) and by the Protocol done at London on 26 September 1997 (Journal of Laws of 2000 No. 202, item 1679), hereinafter known as the „MARPOL Convention”.

All engines used on warships are exempt from compliance with standards of emission of harmful exhaust gases. It should be noted that the percentage of the population of gas turbine engines installed on warships is several times higher in comparison to the civil fleet. However, governments with warship fleets seek to implement the provisions relating to the protection of the marine environment (e.g. MARPOL) on warships as far as it is possible.

Table 1. The emission limit unit values for $\mathrm{NO}_{\mathrm{x}}$ for marine combustionignition engines with power over $130 \mathrm{~kW}$ according to Annex VI to the MARPOL Convention 73/78 [10]

\begin{tabular}{|c|c|c|c|c|}
\hline \multirow{2}{*}{$\begin{array}{l}\text { Emission } \\
\text { level }\end{array}$} & \multirow{2}{*}{$\begin{array}{l}\text { Year of } \\
\text { validity }\end{array}$} & \multicolumn{3}{|c|}{$\begin{array}{c}\mathrm{NO}_{\mathrm{x}} \text { emission limits }[\mathrm{g} /(\mathrm{kWh})] \\
\text { depending on the nominal engine speed } \mathrm{n}[\mathrm{rpm}]\end{array}$} \\
\hline & & $\begin{array}{c}\text { Low Speed } \\
\text { Engine } \\
\mathrm{n}<130\end{array}$ & $\begin{array}{c}\text { Medium Speed } \\
\text { Engine } \\
\mathrm{n} \leq 130<2000\end{array}$ & $\begin{array}{c}\text { High Speed } \\
\text { Engine } \\
\mathrm{n} \geq 2000\end{array}$ \\
\hline I & 2000 & $17.0 *$ & $45.0 \cdot \mathrm{n}^{-0.2} *$ & $9.8 *$ \\
\hline II & 2011 & $14.4 * *$ & $44.0 \cdot \mathrm{n}^{-0.23} * *$ & $7.7 * *$ \\
\hline III & 2016 & $3.4 * * *$ & $9.0 \cdot \mathrm{n}^{-0.2} * * *$ & $2.0 * * *$ \\
\hline \multicolumn{5}{|c|}{$\begin{array}{l}\text { * these values apply to vessels built or those that have undergone } \\
\text { modernization after } 1 \text { January, } 2000 \text { and before } 1 \text { January, 2011, } \\
\text { ** these values apply to any vessel built after } 1 \text { January, 2011, } \\
\text { *** } \text { these values apply to any vessel built after } 1 \text { January 2016. and } \\
\text { sailing in the North American Emission Control Area or Area in } \\
\text { the Caribbean Sea of the United States. }\end{array}$} \\
\hline
\end{tabular}

Ever increasing emission of exhaust gases from marine engines implemented have necessitated the development of new construction concepts of marine power plant of civilian ships and warships. Increasingly, it contemplates the use of gas turbine engines in marine power plant focused on the production of electricity used by electric motors vessel propulsions. In the case of gas turbine engines, the disadvantage is lower efficiency of electricity generation, as evidenced by the high value of the specific fuel consumption (Fig. 1), but the important advantage is the high concentration of generated energy in the unit occupied by the combustion power system volume. The advantage of using gas turbine systems is the ability to supply these motors with so-called light fuels with low sulfur compounds, alternate fuels such as vegetable oil esters, methanol, ethanol, methane and gaseous fuels such as natural gas and propanebutane. 
The use of natural gas to supply the drive marine power plant may be particularly advantageous in LNG transportation ships with this type of fuel. The argument for the use of systems of turbine generators of electricity is the possibility to increase cargo space (Fig. 2) which improves the costeffectiveness ratio of vessel shipment, eliminating the lower overall efficiency of gas turbine engines. It is especially the preferred solution of using light and alternative fuels such as natural gas, propane-butane, vegetable oil esters, methanol or ethanol.
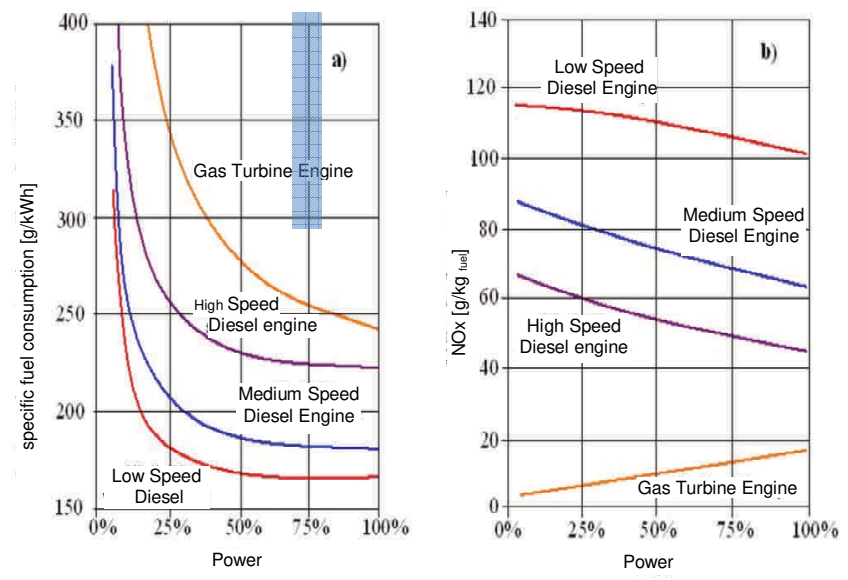

Fig. 1. Specific fuel consumption (a) and $\mathrm{NO}_{\mathrm{x}}$ (b) as a function of the power used for the propulsion types of compression-ignition and gas turbine engines [7]
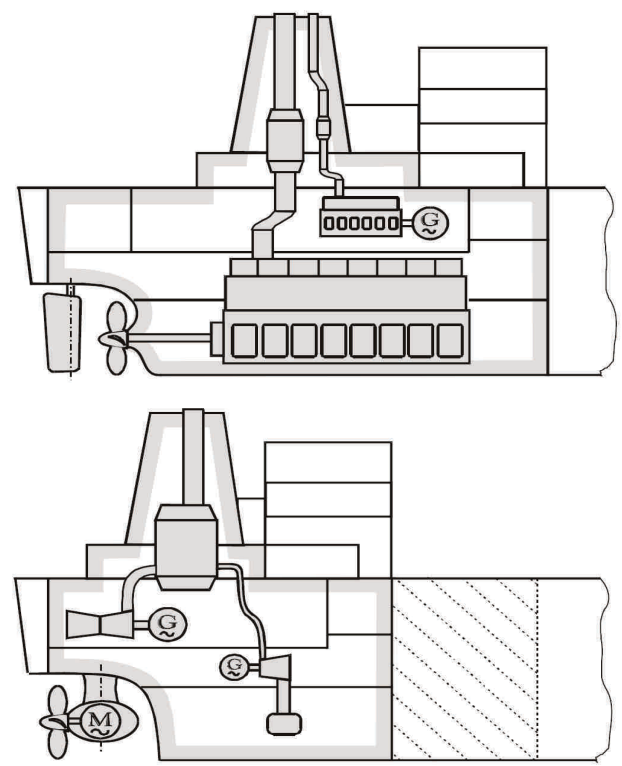

Fig. 2. Comparison of the drive system of the turbine generators of energy in the planned LNG tanker to the traditional direct drive of low-speed compression ignition engine [1]

The concepts of using gas turbine engines is associated with the necessity of accepting higher specific fuel consumption resulting from lower engine efficiency, but also to contribute to obtaining the improvement of ecological indicators in the form of lower emission of harmful fume emissions. Assessment of the real benefits of using gas turbine engines for marine propulsion, obtained under the operating and environmental parameters requires a number of studies and analyzes, some of which are presented in this article.

\section{Characteristics of the unit}

The authors therefore undertake to try to determine the emission of harmful exhaust gases in marine turbine engine, used in the drive system of guided missile frigate class of warship (Fig. 3).

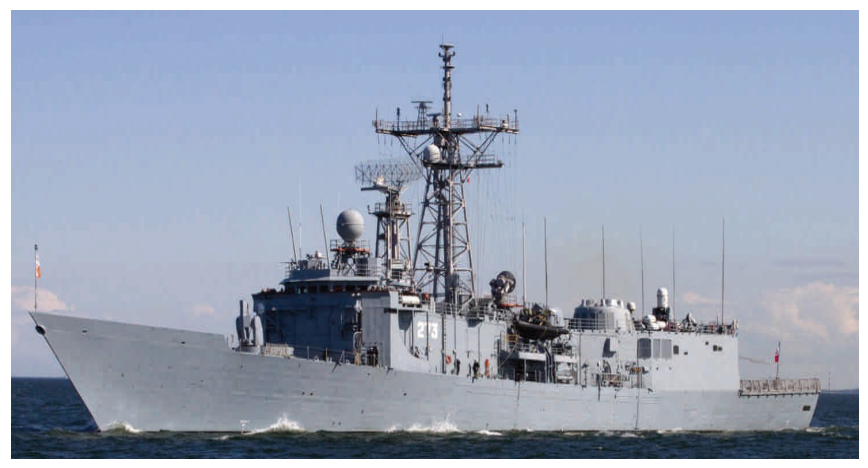

Fig. 3. Oliver Hazard Perry class missile frigate [11]

The propulsion system unit consists of a power unit equipped with two gas turbine engines from General Electric LM 2500 (Fig. 4), a cumulative drive reduction gear ratio of $1 / 20$, one line shaft and adjusting screw. The power of the drive is about $30000 \mathrm{~kW}$ at a maximum turbine propulsion speed of $\mathrm{n}_{\mathrm{TN}}=3600 \mathrm{rpm}$.

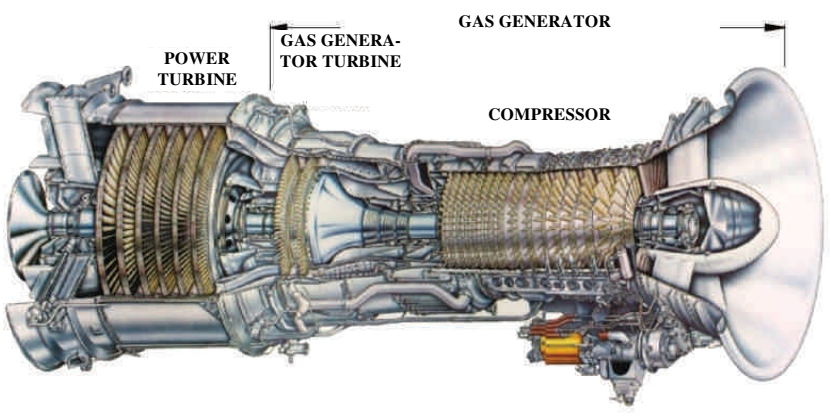

Fig. 4. LM 2500 marine gas turbine engine

Gas turbine engines used in the propulsion system of frigates consist of two rotor units. The basis of engine design is the exhaust gas generator in which the sixteen-axial compressor is driven by a two-stage high-pressure turbine. The first six stages of the compressor are equipped with an adjustable steering blades operating in the range of the $-30^{\circ}$ $-+30^{\circ}$ angular position with an accuracy of $10^{\prime}$. Setting the steering is dependent on the pressure of fuel supplied to the injectors, the rotor speed of the gas generator and the air temperature in the inlet section of the engine. This solution enables the extension of the stable operation of the compressor, especially in transition processes. The continuous combustion process takes place in an annular combustion chamber supplied with fuel through the thirty-two injectors. Six level separate turbine propulsion co-operates with the exhaust gas generator which constitutes a source of mechanical energy for the vessel propulsion system. The engine is entirely located in a casing isolating it from the rest of the power system. This solution was adopted for reasons 
of fire safety and for reducing noise propagation inside the power system. The exhaust system has a length of a several meter vertical channel with a diameter of two meters, ending in narrowing to a diameter of about a meter.

\section{The operating parameters LM 2500 engine}

Measurements of thermal gas-dynamic parameters of the working medium made in specific sections of the engine control are an important source of diagnostic information about the state of the structure of construction part of the flow. The schematic diagram of the LM 2500 engine (Fig. 5) presented with marked control flow sections enables visualization of the distribution points. The measured values and calculation of individual parameters of the engine and the measurement range expressed in units of force in the power system of vessels is summarized in Table 2 .

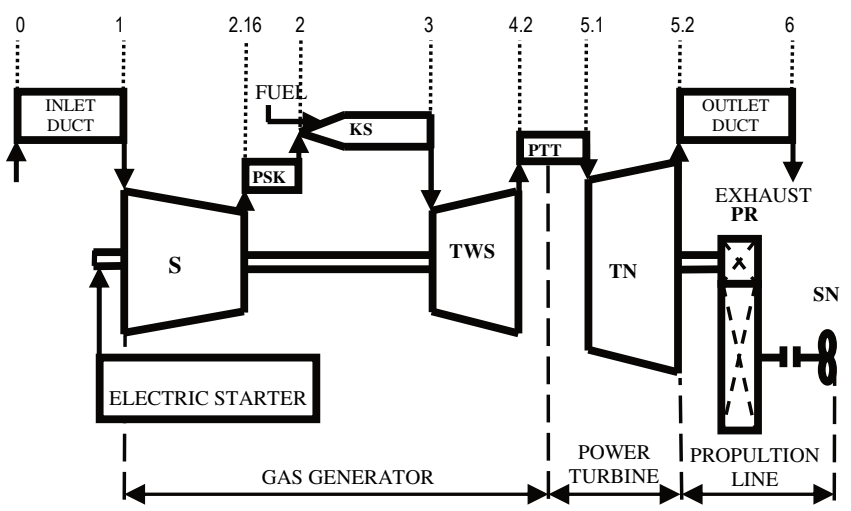

Fig. 5. Block diagram of LM 2500 gas turbine engine

Table 2. Operating parameters LM 2500 engine

\begin{tabular}{|l|c|}
\hline \multicolumn{1}{|c|}{ Name parameter, designation, unit } & Measurement range \\
\hline Barometric pressure $\mathrm{p}_{\mathrm{o}}[\mathrm{hPa}]$ & $800-1040$ \\
\hline Ambient temperature $\mathrm{t}_{\mathrm{o}}\left[{ }^{\circ} \mathrm{C}\right]$ & $-40-+40$ \\
\hline $\begin{array}{l}\text { The rotational speed of the gas generator shaft } \mathrm{n}_{\mathrm{GG}} \\
{[\mathrm{rpm}]}\end{array}$ & $0-12000$ \\
\hline $\begin{array}{l}\text { The rotational speed of the power turbine shaft } \\
\mathrm{n}_{\mathrm{PT}}[\mathrm{rpm}]\end{array}$ & $0-5000$ \\
\hline The inlet air temperature to the engine $\mathrm{t}_{1}\left[{ }^{\circ} \mathrm{F}\right]$ & $-40-+150$ \\
\hline The inlet air total pressure to the engine $\mathrm{p}^{*}{ }_{1}[\mathrm{psig}]$ & $0-16$ \\
\hline Air pressure on the outlet compressor $\mathrm{p}_{2}[\mathrm{psig}]$ & $0-300$ \\
\hline $\begin{array}{l}\text { The temperature of the exhaust stream before the } \\
\text { power turbine } \mathrm{t}_{4.2}\left[{ }^{\circ} \mathrm{F}\right]\end{array}$ & $0-2000$ \\
\hline $\begin{array}{l}\text { Total pressure of the exhaust stream before the } \\
\text { power turbine } \mathrm{p}^{*}{ }_{4.2}[\mathrm{psig}]\end{array}$ & $0-75$ \\
\hline Temperature exhaust gas $\mathrm{T}_{6}\left[{ }^{\circ} \mathrm{F}\right]$ & $0-1000$ \\
\hline The fuel temperature before engine $\mathrm{T}_{\mathrm{f}}\left[{ }^{\circ} \mathrm{F}\right]$ & $0-100$ \\
\hline Pressure fuel injectors before $\mathrm{p}_{\mathrm{f}}[\mathrm{psig}]$ & $0-1500$ \\
\hline $\begin{array}{l}\text { Torque }(\mathrm{calculated}) \text { on the power turbine shaft } \\
\text { MPT }[\mathrm{LB} \text { FT] }\end{array}$ & $0-50000$ \\
\hline Power on the power turbine shaft $\mathrm{P}_{\mathrm{TN}}[\mathrm{KM}]$ & $0-25000$ \\
\hline
\end{tabular}

The location of the turbine engine in the engine room requires the assurance of supply to the inlet of the corresponding mass flow of air and exhaust mass derivation generated from the engine exhaust. Vertical air intake channels and exhaust gas outlet channels (Fig. 6) of about $15 \mathrm{~m}$ have been designed for Oliver Hazard Perry class missile frigate equipped with two LM 2500 turbine engines. The air from the manifold is directed mostly to the inlet of the engine. A small portion of air from the intake side channel is collected and is fed to the interior of the container assembly for the engine in order to ensure a proper temperature around the running engine. Air flowing from the outer parts of the engine in the container housing is ultimately directed into the exhaust duct to be mixed with the gases generated by the turbine engine. Depending on the need to ensure the appropriate parameters, air flowing from the outside of the engine is suitably prepared by an appropriate temperature using the cooling system and the heaters and the flow rate of the respective container inside the housing, controlled by using a fan.

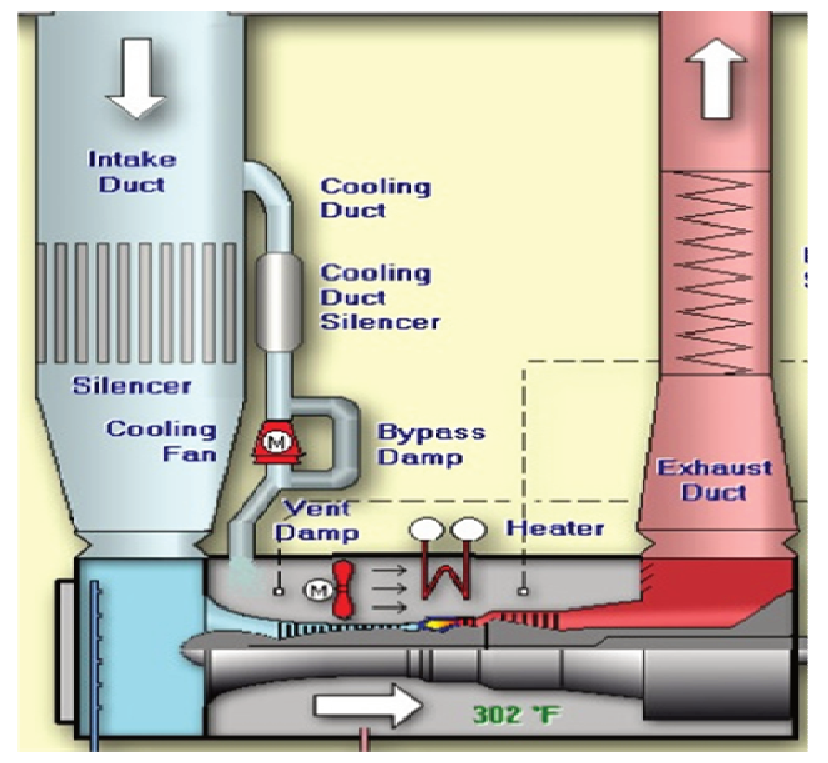

Fig. 6. Arrangement of air intake and LM 2500 engine exhaust outlet mounted on an Oliver Hazard Perry class missile frigate

\section{The operating parameters and the emission of harmful compounds in the exhaust gas turbine engine}

The idea of operating an internal combustion engine is directed in order to achieve the operational performance which translates into propulsion operation. The flow of the exhaust stream generating torque of the power turbine is important for the turbine shaft which eventually results in the drive shaft receiving power from the engine. Parameters values of exhaust gas generated by the so-called generator exhaust - part of the turbine engine - are responsible for the operating parameters obtained from the power turbine shaft. These parameters include mass flow of exhaust gases and the energy described by the temperature and the flow rate at various stages of the turbine. The resulting thermodynamic parameters of the exhaust gas as a working medium are directly dependent on the conditions in the combustion chamber, which are closely related to the operating parameters resulting from the energy requirements. Therefore, there is a relationship between the operating parameters and the conditions of the combustion process occurring in the combustion chamber and the emission of pollutants in the exhaust gas which was generated in order to obtain the required mechanical energy on the drive shaft of the motor.

According to these interdependencies, the emissions contaminants contained in the generated exhaust gases can be evaluated depending on engine load energy. For this 
purpose, it is necessary to specify the mass flow of generated exhaust gases as a function of engine load and concentrations of harmful compounds contained in them. It is necessary to obtain emission characteristics of the engine as a function of load. The issue is familiar and is presented many more studies [3, 4, 6, 9]; however, studies of high power turbine engines require an individual approach, so much so that the issue of the assessment of gas emission from turbine engines is carried out under static conditions at a few selected points of the study and for certification purposes of the engine. In contrast, the evaluation of pollutant emissions, carried out by the authors, in the exhaust gases of the turbine engine shaft used at sea is focused on the evaluation of the operating conditions of the vessel during the voyage being undertaken.

In order to determine the characteristics of the LM 2500 engine emission, it is necessary to estimate the generated mass flow of exhaust gases. The mass flow of exhaust gases is the total flow of air and fuel supplied to the engine. Therefore, it is necessary to designate the mass flow of air and the mass flow of fuel. When available, the possible measured values of engine operating parameters LM 2500 can be troublesome. Therefore, the calculation of one of these values and measuring the excess air ratio for the engine carried out in the combustion process using a broadband oxygen sensor is a necessary condition. By knowing the ratio of the air-fuel consumption, the air or engine fuel according to which the value is obtained from the measurement can be established. Establishing the exhaust gas mass can be linked to the value of concentrations of harmful compounds, thus obtaining the emission of pollutants in the exhaust gases. In carrying out the emission characteristics of the engine as a function of load, it is necessary to obtain the dependent equation that can be used in the algorithm for determining the instantaneous emission engine operating conditions. Examples of the emission characteristics have been developed by the authors on the basis of the GTD-350 turbine engine shaft [7] and the resulting equations describe the changes of the concentration of the individual compounds as a function of load (Fig. 7). The distribution of received values and dependencies should be considered as an example of a distribution of received values of described equations are a feature of its own motor. Therefore, it is necessary to determine the emission for the engine, for which assessment of emission standards in operating conditions shall be undertaken in the subsequent stage. It is necessary to associate the obtained dependencies on the operating parameters of the engine in order to make such evaluation, i.e. the engine-generated power, the speed of rotation of the shaft gas generator, the rotational speed of the power turbine shaft, rotational speed and screw settings of the ship propeller, and the sailing speed of the vessel and the parameters of the course as a further step.

With the increase in engine power demand, the combustion temperature rises, thereby increasing the concentration of nitrogen oxides $\left(\mathrm{NO}_{\mathrm{x}}\right)$ in the exhaust gas. As the engine power increases, the concentration of carbon monoxide (CO) decreases. Carbon monoxide is an incomplete combustion product, and therefore, when it comes to the lack of air for burning fuel, it occurs. Therefore, with increasing power of the engine carbon monoxide will be less and less. At higher temperatures carbon monoxide oxidizes to carbon dioxide $\left(\mathrm{CO}_{2}\right)$, which results in an increase in carbon dioxide emissions.
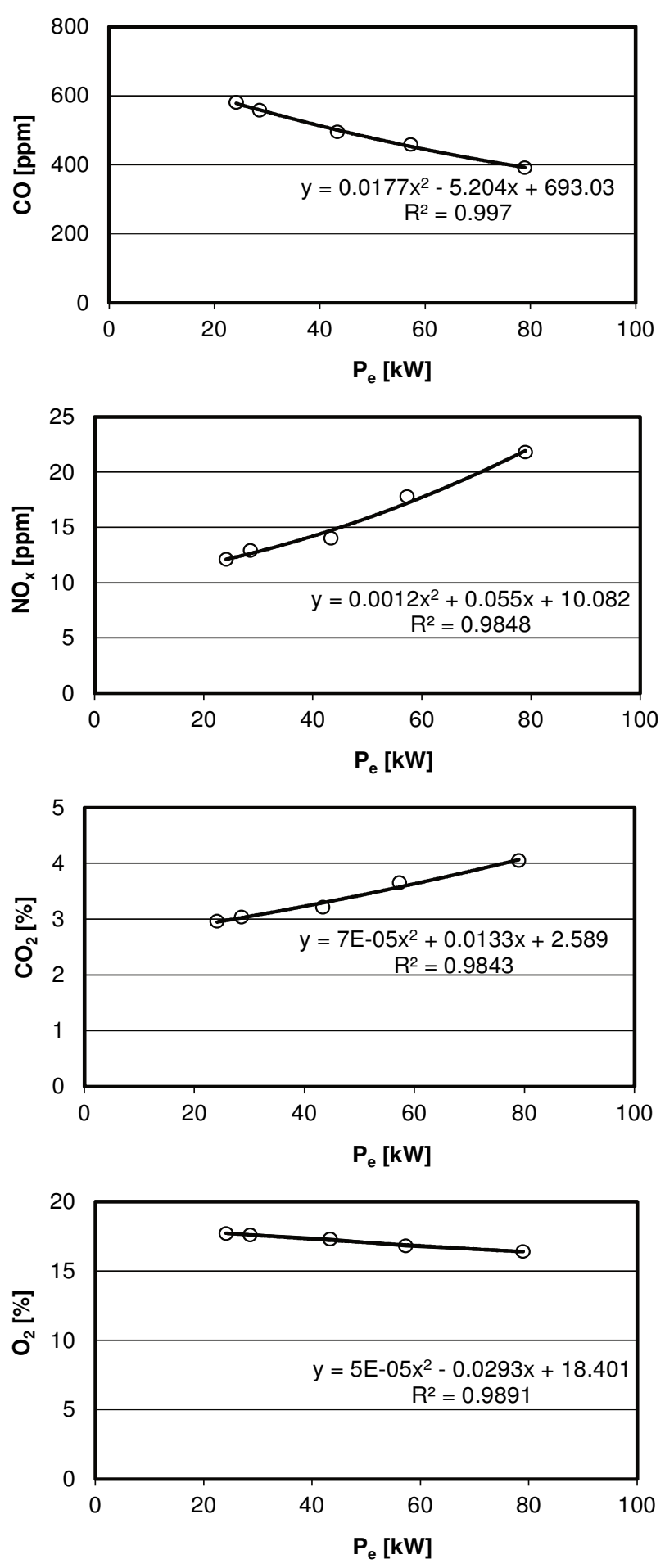

Fig. 7. Examples of the concentration of selected components of the exhaust gas as a function of the power of GTD-350 gas turbine engine

Taking into account available parameters monitored in the engine room, the following one can be used:

- rotor speed of gas generator,

- the rotational speed of the separate power turbine, 
- the temperature of the inlet air to the engine,

- the total pressure of the inlet air to the engine,

- the temperature of the exhaust gas stream before the turbine engine,

- the total pressure of the exhaust gas stream upstream of the turbine engine,

- output torque of the power turbine,

- power on the power turbine shaft.

Other information should be obtained using the measurement system of excess air, and using apparatus for testing the concentration of pollutants in the exhaust gas.

\section{Summary}

The analysis of the monitored operating parameters in the engine room the Oliver Hazard Perry guided missile frigate class which is in the service of the Polish Navy, highlighting the need for additional equipment and mathematical algorithms to determine the level of performance necessary to assess pollutant exhaust gas generated by the turbine engine shaft of the main drive. This evaluation requires earlier studies related to obtaining emission characteristics of the engine for all of its operations. However, the supplemented characteristics of the algorithm determine the mass flow of exhaust allow it to derive the emission of harmful compounds in the operating conditions of the vessel.

\section{Nomenclature}

S compressor

KS combustor

TWS gas generator turbine

$\mathrm{TN}$ power turbine
PR reduction gear

SN propeller

PSK space between $\mathrm{S}$ and KS

PTT space between TWS and TN

\section{Bibliography}

[1] HOUNTALAS, D.T., KOUREMENOS, A.D. Development of fast and simple simulation model for the fuel injection system of diesel engines. Advanced in Engineering Software. 1998, 26(1), 13-28.

[2] HOUNTALAS, D.T., KOUREMENOS, A.D. Development of fast and simple simulation model for the fuel injection system of diesel engines. Advanced in Engineering Software. 1998, 26(1), 13-28.

[1] GIERNALCZYK, M., GÓRSKI, Z. Ship engine rooms, part I, fundamentals of drive and energy ship. Publisher Gdynia Maritime University. Gdynia 2011.

[2] GŁOWACKI, P., SZCZECIŃSKI, S. Turbine jet engine as a source of environmental threats. The work of the Institute of Aviation. 2011, 213.

[3] KNIAZIEWICZ, T. Process modeling of ship emissions of internal combustion engines for main propulsion under real operating conditions. Publisher Academic AMW. Gdynia 2013.

[4] KOTLARZ, W. ed. Group work, turbine powertrains source of air pollution at military airports. Publisher WSOSP. Deblin 2003.

Paweł Wirkowski, MSc. - Faculty of Mechanical and Electrical Engineering at Polish Naval Academy. e-mail: P.Wirkowski@amw.gdynia.pl
[5] KOWALEWICZ, A. Fundamentals of combustion processes. Publisher Scientific-Technical. Warszawa 2000.

[6] MARKOWSKI, J. Exhaust emission from aircraft piston engines. Publisher Poznan University of Technology. Poznan 2013.

[7] MARKOWSKI, J., PIELECHA, J., JASIŃSKI, R. et al. Evaluation of relations operating and ecological parameters of turbine engines. Journal of Polish CIMEEAC. 2015, 10(1).

[8] MERKISZ, J., MARKOWSKI, J., ŚLUSARZ, G. et al. Comparative analysis of exhaust emission test for a turbine engine. Combustion Engines. 2015, 162.

[9] MERKISZ, J., PIASECZNY, L., KNIAZIEWICZ, T. Issues emissions of marine engines. Publisher Poznan University of Technology. Poznan 2016.

[10] The International Convention for the Prevention of Pollution from Ships, 1973/1978 MARPOL. Publisher PRS. Gdansk 2015.

[11] www.google.pl/search?q=fregata +273 .

Tomasz Kniaziewicz, DSc., DEng. - Faculty of Mechanical and Electrical Engineering at Polish Naval Academy.

e-mail:T.Kniaziewicz@amw.gdynia.pl 